\title{
UNA NUEVA ESPECIE DE TAUSCHIA (UMBELLIFERAE) DEL ESTADO DE MEXICO ${ }^{\circ}$
}

\section{GRACIELA CALDERON DE RZEDOWSKI ${ }^{* *}$ LINCOLN CONSTANCE ${ }^{\circ \circ}$}

Como resultado de las continuas exploraciones que se efectuan con el objeto de preparar la Flora Fanerogámica del Valle de México, se han ido colectando varias plantas desconocidas hasta el momento. Este ha sido el caso de unos ejemplares pertenecientes al género Tauschia, dentro de la familia de las Umbelíferas.

Tauschia neglecta, sp. nov. Plantae graciles brevi-caulescentes e caudicibus gracilibus interdum foliis exsiccatis persistentibus vestitis, foliis inflorescentiisque minute scaberulis; folia basalia ovalia vel ovata bi- vel tripinnatisecta, divisionibus ultimis linearibus; petioli graciles anguste vaginantes; folia caulina pauca reducta sessilia; pedunculi patenti-adscendentes folia excedentes; involucrum nullum; radii fertiles patenti-adscendentes subaequales; involucelli bracteolis linearibus usque ad ovatis vel rhombeis scarioso-marginatis integris trilobisve; pedicelli fertiles crassi breves; flores citrini; styli breves, stylopodio evidenti depresso-conico; carpophorum crassum bipartitum; fructus lanceolato-ovoideus vel ovoideus ad apicem versus acutus basi rotundatus, costis humilibus rotundatisque pallidis intervallis fuscis subaequalibus; vittae parvae numerosae; seminum superficie involuta; chromosomatum numerus $n=22$; cotyledones lanceolatae.

Planta herbácea delgada, de 1 a $4 \mathrm{dm}$ de alto, cortamente caulescente, raíz pivotante engrosada terminando en un cáudice delgado, ramificado, que a veces conserva las bases persistentes de las hojas del año anterior, con pubescencia escabérula en el follaje que es ligeramente glauco y en especial en la inflorescencia; hojas ovales u ovadas, de 3 a $10 \mathrm{~cm}$ de largo por 2 a $8 \mathrm{~cm}$ de ancho, bi- o tripinnatisectas con las divisiones lineares, agudo-mucronuladas, las últimas divisiones uninervadas, de 1 a $5 \mathrm{~mm}$ de largo por más o menos $0.5 \mathrm{~mm}$ de ancho; peciolos de 4 a $10 \mathrm{~cm}$ de largo, delgados, estrechamente envainantes en la base; hojas caulinas 0 a 3, completamente envainantes, las vainas inconspicuamente dilatadas; inflorescencia de varias umbelas terminales compuestas, pedúnculos delgados, de 5 a $25 \mathrm{~cm}$ de largo, ascendentes-extendidos, escabérulos debajo de la umbela; invólucro ausente; radios fértiles 2 a 8 , delgados, subiguales, ascendentesextendidos, escabérulos, de 1 a $3 \mathrm{~cm}$ de largo; involucelo de 2 a 5 bracteolas enteras o trilobadas, hasta de $3 \mathrm{~mm}$ de largo, lineares a ovadas o rómbicas, con márgenes escariosas; pedicelos fértiles 2 a 5 , robustos, de 1 a $2 \mathrm{~mm}$ de largo, glabros; flores amarillas, cáliz obsoleto, pétalos obovado-espatulados, anteras amarillas; estilopodio en forma de cono deprimido, estilos cortos, recurvados, de unos $0.5 \mathrm{~mm}$ de largo;

- Trabajo parcialmente subvencionado por el Consejo Nacional de Ciencia y Tecnología, en el marco del proyecto "Flora y Vegetación del Valle de México".

- Laboratorio de Botánica Fanerogámica. Escuela Nacional de Ciencias Biológicas. Instituto Politécnico Nacional. México 17, D.F.

○० Departament of Botany. University of California. Berkeley, California 94720. 


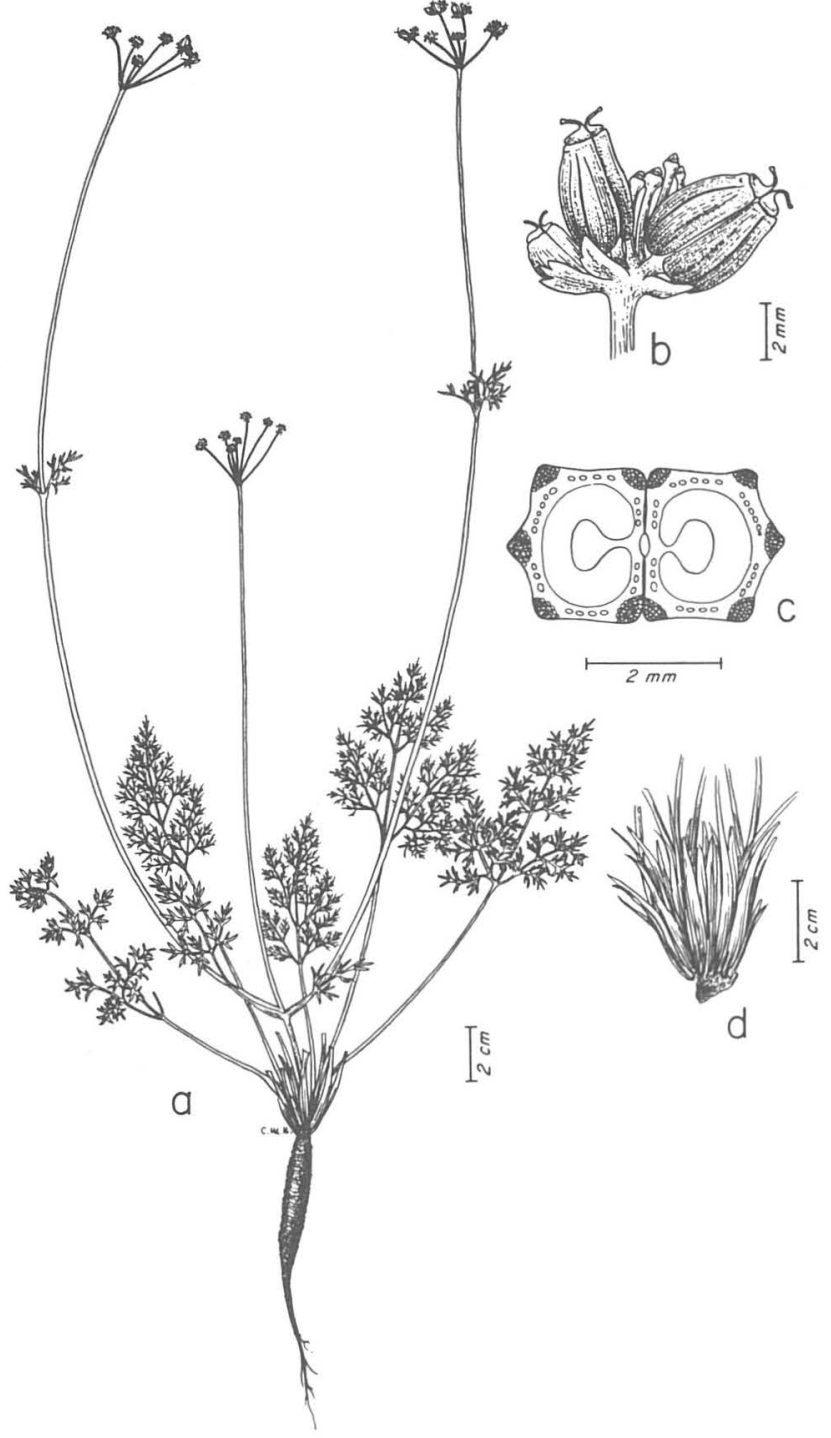

Fig. 1. a. Aspecto de la planta; b. Frutos; c. Corte transversal de fruto; d. Aspecto de la roseta con las bases persistentes de las hojas. 
carpóforo bipartido, las ramas robustas, aplicadas; fruto ovoide, de 5 a $6 \mathrm{~mm}$ de largo por 2 a $4 \mathrm{~mm}$ de ancho, angostándose hacia el ápice, redondeado en la base, glabro, con las costillas prominentes, muy corchosas y de color pálido, subiguales, bajas y redondeadas, sin alas, más angostas que los intervalos; tubos oleíferos pequeños, 2 a 5 en los intervalos, 4 a 8 en la comisura; semillas con la cara comisural involuta; número cromosómico $n=22$; cotiledones lanceolados, de $2 \mathrm{~cm}$ de largo por $0.5 \mathrm{~mm}$ de ancho.

TIPO: MEXICO: ESTADO DE MEXICO: Cerca de Lanzarote, Municipio de Villa Nicolás Romero, pastizal, cerca de cultivo. Alt. $2350 \mathrm{~m}$. 31-VII-1977, J. Rzedowski 35009 (ENCB: holotipo; UC: isotipo). Otras colecciones revisadas, todas de la misma área general, son las siguientes: $1 \mathrm{~km}$ al E de Lanzarote, orilla de arroyo, 1-V-1974, J. Rzedowski 31879 (ENCB, UC); orilla de cultivo, 2-VIII1977, Irene García González s.n. (ENCB).

Fuera de esta restringida zona, la especie ha sido colectada en: "Between San Juan del Río and Mexico City, Hwy 57, State of Mexico north of $\mathrm{km}$ 111 to Mexico City, uncultivated farm land, flat, loam-gravel, $2500 \mathrm{~m}$ alt., 17-VII-1979, Amy Jean Gilmartir et al. 2377 (UC).

Las plantas más afines a $T$. neglecta, parecen ser especies acaules tales comı T. filiformis (Coult. \& Rose) Coult. \& Rose, de Oaxaca y T. seatonii (Coult. \& Rose) Coult. \& Rose, de Orizaba. El estilopodio deprimido pero claramente evidente en el fruto, se presenta también en estas dos especies, las que originalmente habían sido referidas a Arracacia por esta característica. Se puede sugerir una afinidad más lejana con las siguientes especies: T. madrensis Coult. \& Rose, de Chihuahua y Durango, T. tenuifolia (S. Wats.) Math. \& Const., de Chihuahua y T. steyermarkii Math. \& Const., de Guatemala, pero estos tres taxa tienen estilos delgados y carecen completamente de estilopodio.

Los autores agradecen al Dr. Tsan-Iang y a Fei-mei Chuang por el recuento cromosómico, el que se obtuvo a partir de semilla de la colección tipo, cultivada en el Jardín Botánico de la Universidad de California, en Berkeley, bajo la designación C-2044. Desean también expresar su reconocimiento a Charlotte Mentges Hannan por las ilustraciones.

\section{RESUMEN}

Se describe e ilustra Tauschia neglecta sp. nov., en base a ejemplares colectados en el Estado de México. Su número cromosómico se determinó como $n=22$. T . neglecta parece estar relacionada con $T$. filiformis (Coult. \& Rose) Coult. \& Rose conocida de Oaxaca y con T. seatonii (Coult. \& Rose) Coult. \& Rose conocida de Orizaba.

\section{SUMMARY}

Tauschnia neglecta sp. nov. is described and illustrated on the basis of specimens collected in the State of México. Its chromosome number was determinated as $n=22$. T. neglecta seems to be related to $T$. filiformis (Coult. \& Rose) Coult. \& Rose known from Oaxaca and with T. seatonni (Coult. \& Rose) Coult. \& Rose known from Orizaba. 